\title{
SCAMP: Rapid Focused Sonic Boom Waypoint Flight Planning Methods, Execution, and Results ${ }^{1.2}$
}

\author{
Edward A. Haering Jr., ${ }^{3}$ Larry J. Cliatt II, ${ }^{4}$ and Michael M. Delaney Jr. ${ }^{5}$ \\ NASA Dryden Flight Research Center, Edwards, California, 93523 \\ Kenneth J. Plotkin ${ }^{6}$ \\ Wyle, Arlington, Virginia, 22202 \\ Domenic J. Maglieri ${ }^{7}$ \\ Eagle Aeronautics, Inc., Newport News, Virginia, 23606 \\ Jacob C. Brown ${ }^{8}$ \\ Tybrin Corporation, Edwards, California, 93523
}

\begin{abstract}
Successful execution of the flight phase of the Superboom Caustic Analysis and Measurement Project (SCAMP) required accurate placement of focused sonic booms on an array of prepositioned ground sensors. While the array was spread over a 10,000-ft-long area, this is a relatively small region when considering the speed of a supersonic aircraft and sonic boom ray path variability due to shifting atmospheric conditions and aircraft trajectories. Another requirement of the project was to determine the proper position for a microphone-equipped motorized glider to intercept the sonic boom caustic, adding critical timing to the constraints. Variability in several inputs to these calculations caused some shifts of the focus away from the optimal location. Reports of the sonic booms heard by persons positioned amongst the array were used to shift the focus closer to the optimal location for subsequent passes. This paper describes the methods and computations used to place the focused sonic boom on the SCAMP array and gives recommendations for their accurate placement by future quiet supersonic aircraft. For the SCAMP flights, $67 \%$ of the foci were placed on the ground array with measured positions within a few thousand feet of computed positions. Among those foci with large caustic elevation angles, $96 \%$ of foci were placed on the array, and measured positions were within a few hundred feet of computed positions. The motorized glider captured sonic booms on 59\% of the passes when the instrumentation was operating properly.
\end{abstract}

\section{Nomenclature}

$\mathrm{AB}=$ afterburner

$a \quad=$ speed of sound, $\mathrm{ft} / \mathrm{s}$

\footnotetext{
${ }^{1}$ Note that the use of trade names or names of manufacturers in this document does not constitute an official endorsement of such products or manufacturers, either express or implied, by the National Aeronautics and Space Administration.

${ }^{2}$ This material is declared a work of the U.S. Government and is not subject to copyright protection in the United States.

${ }^{3}$ Aerospace Engineer, Research Aerodynamics, MS 2228, P.O. Box 273, AIAA nonmember.

${ }^{4}$ Aerospace Engineer, Research Aerodynamics, MS 2228, P.O. Box 273, AIAA nonmember.

${ }^{5}$ Electronics Engineer, Research Instrumentation, MS 2228, P.O. Box 273, AIAA nonmember.

${ }^{6}$ Chief Scientist, Environmental and Energy Research \& Consulting, $20012^{\text {th }}$ Street, Suite 900, AIAA Senior

Member.

${ }^{7}$ Projects Director, 732 Thimble Shoals Blvd., Bldg. C-204, AIAA Associate Fellow.

${ }^{8}$ Instrumentation Engineer, Research Instrumentation, MS 2228, P.O. Box 273, AIAA nonmember.
} 


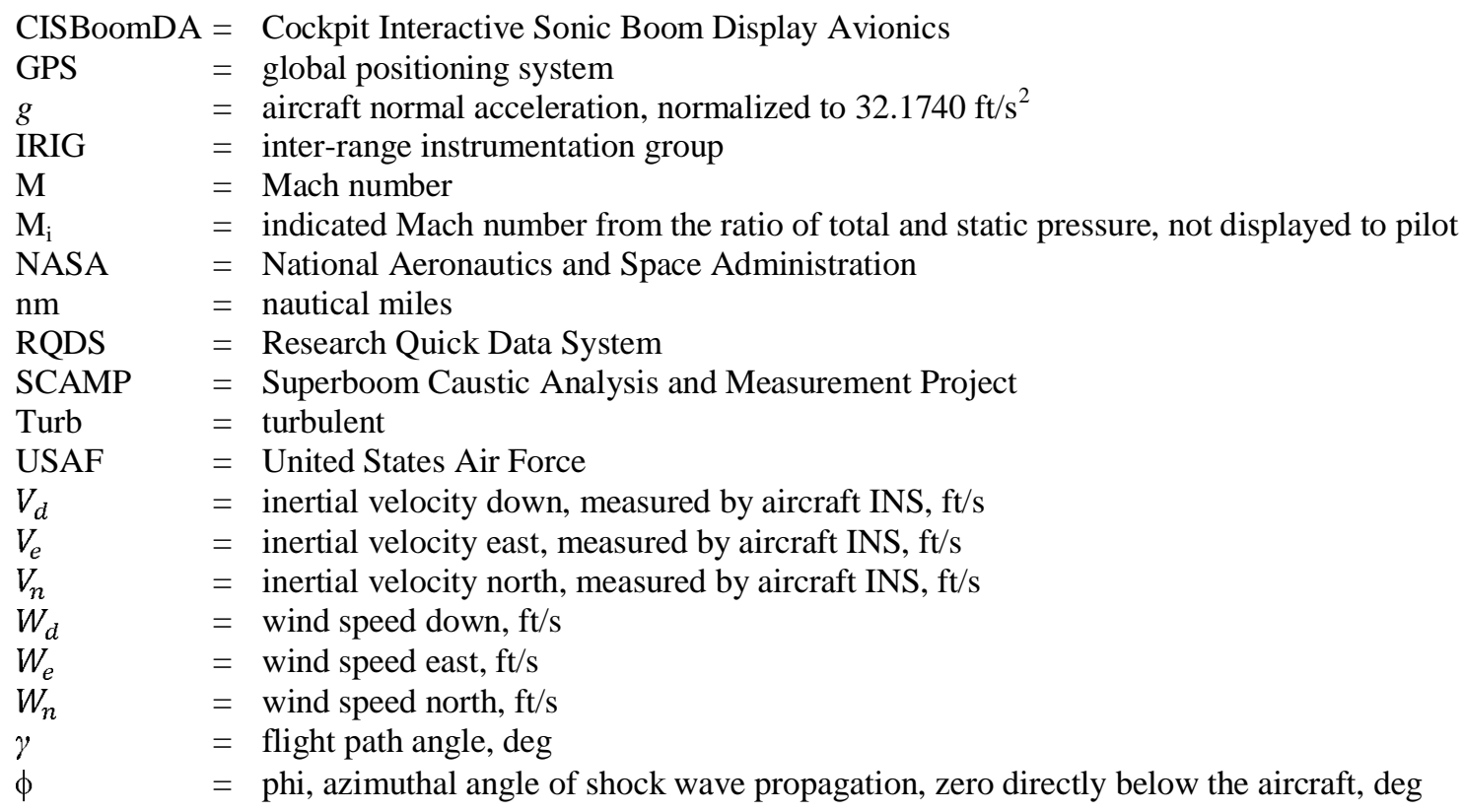

\section{Introduction}

$\mathrm{T}$ he SCAMP microphone array length and density was shaped by several factors. The first factor was the number of high-quality microphones and recording channels available to the project members: approximately 81 microphones. The second factor was the length of the geographical area available to the test team: 10,000 ft. The third factor, which meshed well with the first two factors, was the fact that the ground-level sonic boom signature of an F-18 airplane (McDonnell Douglas, now The Boeing Company, Chicago, Illinois) is approximately $125 \mathrm{ft}$ long, which is the same length as $10,000 \mathrm{ft}$ divided by the 80 gaps between the microphones. Figure 1 shows an entire sonic boom footprint from one of the SCAMP maneuvers, with the array denoted by the numbers 0 and 80 on the centerline straddling the focus. The sonic boom centerline raypaths (shown as cyan curves), caustic (shown as a red surface), and footprint are computed using PCBoom6 $^{1}$ which performs sonic boom raytracing computations for given aircraft trajectory, atmospheric profile, and geographical information.

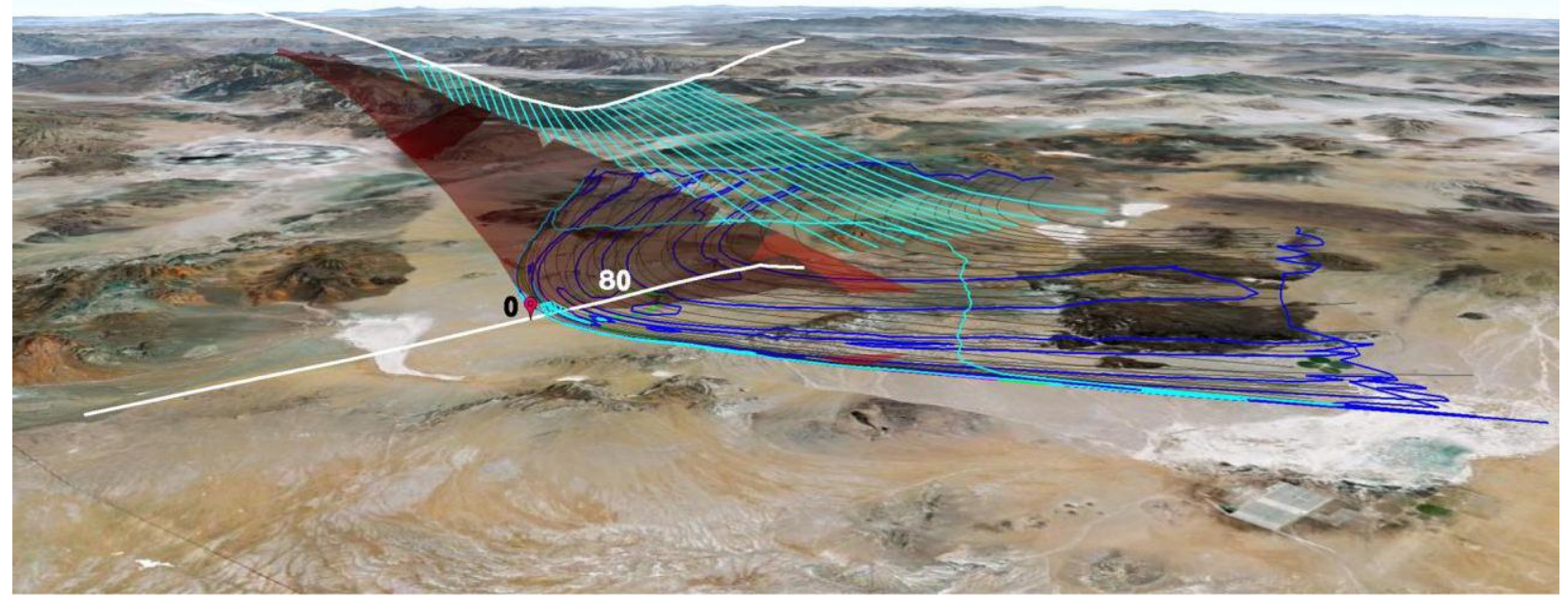

Figure 1. The SCAMP pushover maneuver, showing flight trajectory and ground track as white lines. 
The region near the microphone array is shown in Fig. 2. The optimal location for focused sonic boom placement was $25 \%$ along the array, which was microphone number 20 . There are three tethered blimp microphones shown, denoted as BH, BM, and BL; however, measurements by the blimp are not discussed in this paper. Microphone numbers 67 through 70 needed to be shifted slightly off the array to avoid the nest of a Western Burrowing Owl (Athene cunicularia hypugaea); this owl is protected in the United States and Mexico by the Migratory Bird Treaty Act).

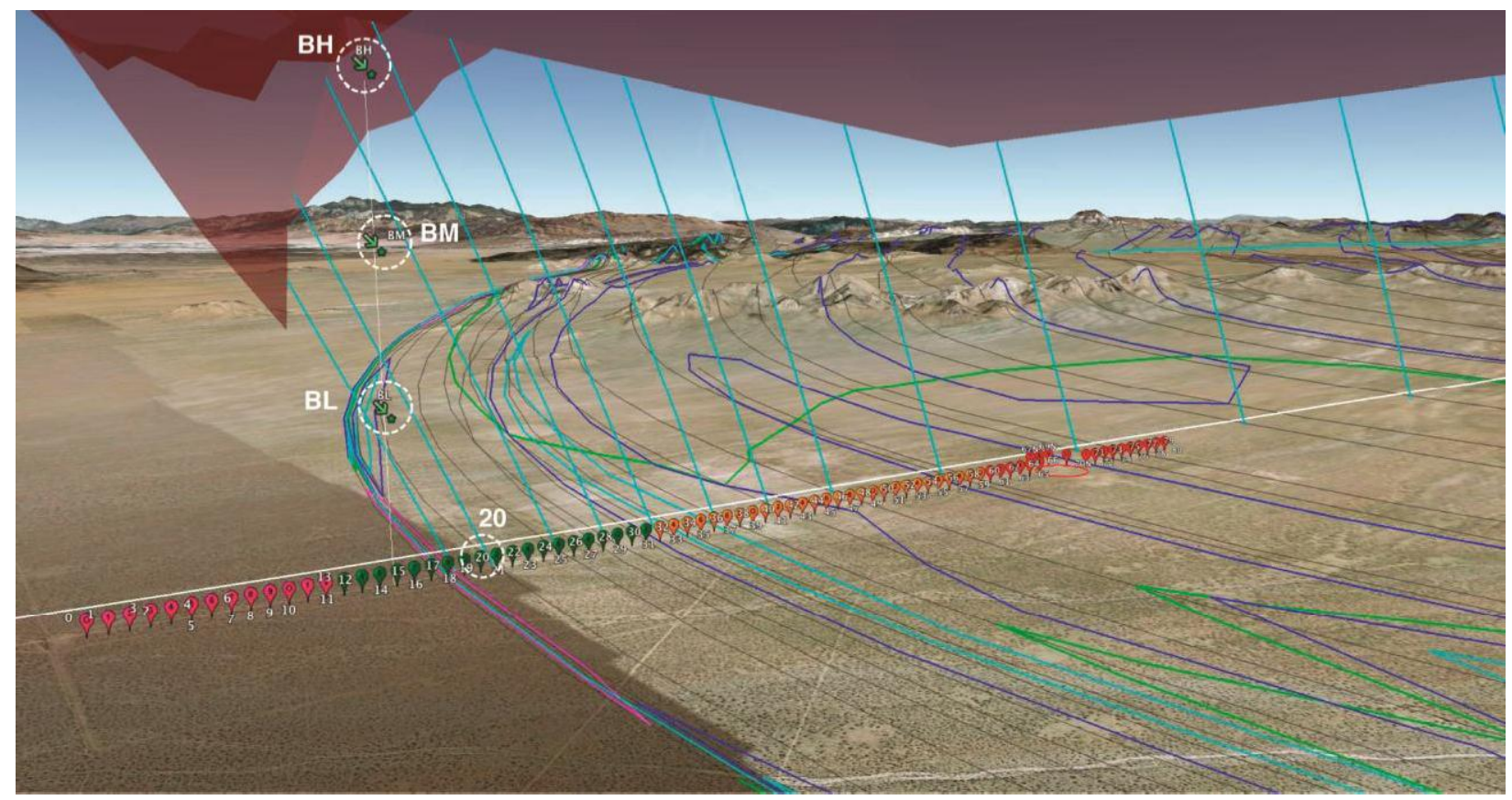

Figure 2. Closeup of Fig. 1 showing focused sonic boom near microphone number 19, close to the optimal location of microphone number 20. The nominal tethered blimp microphones are also shown. The uptrack direction is toward lower-numbered microphones and the downtrack direction is toward higher-numbered microphones. The gray arcs on the ground are isopemps: the loci of boom impact points that were generated at equal times.

Other flight efforts have also measured focused sonic booms, but generally at lower altitudes and with a lower number of maximum focused sonic booms measured. For historical perspective, Table 1 summarizes previous and current focused sonic boom measurements efforts around the world. Flights performed at relatively low altitude, such as the Jericho Focalisation and the Have BEARs projects, have very high percentages of booms placed on the array because the atmosphere plays a much smaller role in propagation uncertainty at lower flight altitudes. 
Table 1. Compilation of the focused sonic boom experiments.

\begin{tabular}{|c|c|c|c|c|c|c|c|c|c|}
\hline Sponsor & England & NASA/USAF & NASA & France & France & France & $\begin{array}{l}\text { NASA } \\
\text { / USAF }\end{array}$ & USAF & NASA \\
\hline Name & - & - & - & $\begin{array}{c}\text { Jericho } \\
\text { Focalisation } \\
\end{array}$ & $\begin{array}{l}\text { Jericho } \\
\text { Virage } \\
\end{array}$ & $\begin{array}{l}\text { Jericho } \\
\text { Carton } \\
\end{array}$ & $\begin{array}{c}\text { Bren } \\
\text { Tower }\end{array}$ & $\begin{array}{c}\text { Have } \\
\text { BEARs }\end{array}$ & SCAMP \\
\hline Year & 1959 & 1961 & 1964 & 1966 & 1967 & 1969 & 1970 & 1994 & 2011 \\
\hline Aircraft & $\begin{array}{l}\text { Fairey } \\
\text { Delta } 2\end{array}$ & F-104 & F-104 & Mirage III & $\begin{array}{l}\text { Mirage } \\
\text { IV }\end{array}$ & $\begin{array}{l}\text { Mirage } \\
\text { III \& } \\
\text { IV }\end{array}$ & F-104 & F-16B & F-18B \\
\hline $\begin{array}{l}\text { Number of } \\
\text { passes }\end{array}$ & 7 & 7 & 5 & 12 & 5 & 23 & 26 & 31 & 70 \\
\hline $\begin{array}{l}\text { Flight altitude, } \\
\text { ft }\end{array}$ & 10,000 & 14,200 & 37,000 & 2000 & 36,000 & 36,000 & 33,700 & 10,000 & $\begin{array}{c}35,000- \\
45,000\end{array}$ \\
\hline $\begin{array}{l}\text { Mach number } \\
\text { range }\end{array}$ & $0.98-1.2$ & $0.9-1.2$ & $0.9-1.5$ & $0.97-1.06$ & $\begin{array}{l}1.05- \\
1.03\end{array}$ & $\begin{array}{c}1.05- \\
1.3\end{array}$ & $\begin{array}{c}0.95- \\
1.3\end{array}$ & $0.9-1.2$ & $1.1-1.3$ \\
\hline $\begin{array}{l}\text { Acceleration } \\
\text { rates, } \mathbf{m} / \mathrm{s}^{\wedge} 2\end{array}$ & $\operatorname{Max} \mathrm{AB}$ & $\operatorname{Max} \mathrm{AB}$ & $\operatorname{Max} \mathrm{AB}$ & $3(\operatorname{Max} A B)$ & $0.3-1.2$ & $0.2-1.2$ & $1.1-1.6$ & Max AB & Variable \\
\hline $\begin{array}{l}\text { Array length, } \\
\text { ft }\end{array}$ & 6000 & 8500 & 116,000 & 9850 & 9850 & 16,000 & 3200 & $\begin{array}{c}10,500- \\
13,700 \\
\end{array}$ & 10,000 \\
\hline $\begin{array}{l}\begin{array}{l}\text { Number of } \\
\text { microphones }\end{array} \\
\end{array}$ & 6 & 4 & 8 & 28 & 28 & 48 & 14 & $15-21$ & 81 \\
\hline $\begin{array}{l}\text { Microphone } \\
\text { spacing, ft }\end{array}$ & 1300 & 2800 & $\begin{array}{c}5000 \\
10,000 \\
20,000 \\
\end{array}$ & 330 & 330 & 394 & 200 & $\begin{array}{c}500 \& \\
2000 \\
\end{array}$ & 125 \\
\hline $\begin{array}{l}\begin{array}{l}\text { Lateral } \\
\text { measurement }\end{array} \\
\end{array}$ & None & None & None & None & None & $\begin{array}{c}\text { To } 6.2 \\
\text { mi one } \\
\text { side } \\
\end{array}$ & $\begin{array}{c}0.34 \mathrm{mi} \\
\text { to each } \\
\text { side } \\
\end{array}$ & None & $\begin{array}{c}25^{\circ}, 30^{\circ}, \\
35^{\circ} \text { one } \\
\text { side }\end{array}$ \\
\hline $\begin{array}{l}\text { Above-ground } \\
\text { measurements }\end{array}$ & None & None & None & None & None & None & $\begin{array}{c}15 \\
\text { every } \\
100 \mathrm{ft}\end{array}$ & None & $\begin{array}{c}2500 \text { and } \\
7500 \mathrm{ft}\end{array}$ \\
\hline $\begin{array}{l}\text { Measured } \\
\text { focus factor }\end{array}$ & - & $2.0-2.5$ & 2.5 & 5 & 5.6 & 6 & $2.0-5.0$ & $2.0-4.2$ & $3-5$ \\
\hline $\begin{array}{l}\text { Focus placed } \\
\text { on array }\end{array}$ & - & 1 of 7 & 2 of 5 & 12 of 12 & 4 of 5 & $\begin{array}{c}11 \text { of } \\
23\end{array}$ & $\begin{array}{c}15 \text { of } \\
26\end{array}$ & 26 of 31 & 37 of 61 \\
\hline $\begin{array}{l}\text { Maximum } \\
\text { focus } \\
\text { measured }\end{array}$ & None & None & None & 2 of 2 & None & 1 of 23 & None & None & 37 of 61 \\
\hline Reference & 2 & 3 & 4 & 5 & 6 & 7 & 8 & 9 & $\begin{array}{c}\text { This } \\
\text { paper }\end{array}$ \\
\hline
\end{tabular}

Another requirement of the project was to determine the proper position for a microphone-equipped TG-14 motorized glider (AMT 200S Ximango, Grupo Aeromot, Porto Alegre, Brazil), tail number 149, to intercept the sonic boom caustic, adding critical timing to the constraints. Variability in several inputs to these calculations caused some shifts of the focus away from the optimal location. Reports of the sonic booms heard by persons spread over the array were used to shift the focus closer to the optimal location for subsequent passes. This paper describes the methods and computations used to place the focused sonic boom on the SCAMP array, the results of calculated versus measured focused sonic boom locations, and recommendations for accurate placement of focused sonic booms for future quiet supersonic aircraft.

\section{F-18B Instrumentation and Displays}

The NASA Dryden F-18B airplane, tail number 852, shown in Fig. 3, was used to generate the sonic booms for SCAMP. The external mold line of this airplane is the same as that of a standard F-18B airplane with a centerline fuel tank installed. Internally this aircraft is equipped with a Research Quick Data System (RQDS) that converts the airplane 1553 bus data into pulse-code modulation (PCM) data for telemetry and onboard recording. Additionally global positioning system (GPS) -based IRIG-B timecode generator data were recorded. A ruggedized Ethernet gateway was used to convert the PCM data into an Ethernet data stream that was fed to a rugged tablet personal computer in the rear cockpit seat to display the first time derivative of Mach number and flight path angle. This display is referred to as the MDot display, shown installed in the F-18 simulator in Fig. 4 and in the F-18B airplane, in Fig. 5. 


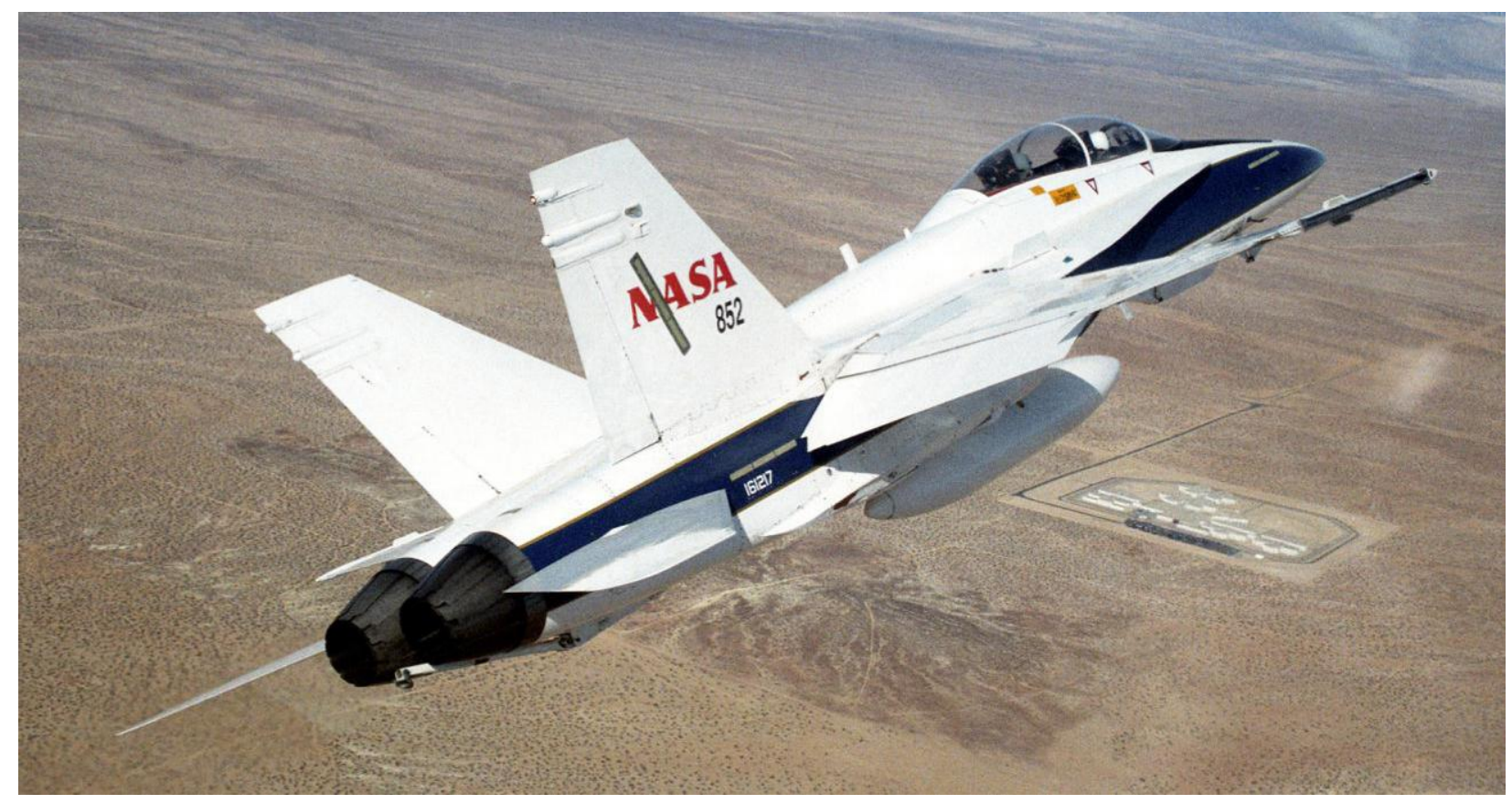

Figure 3. The F-18B airplane, tail number 852, with the centerline fuel tank installed.

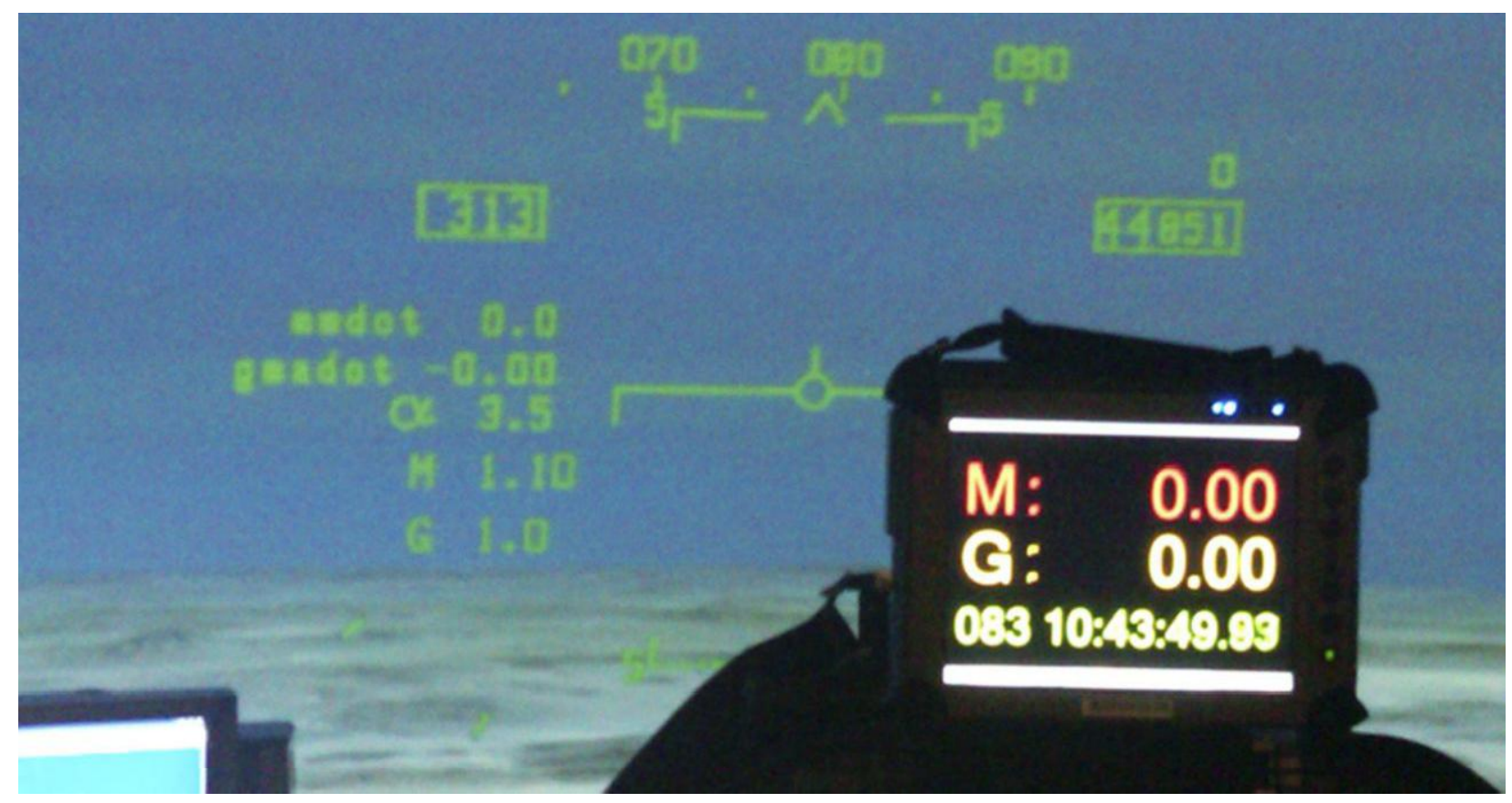

Figure 4. The MDot display mounted in the F-18 simulator. 


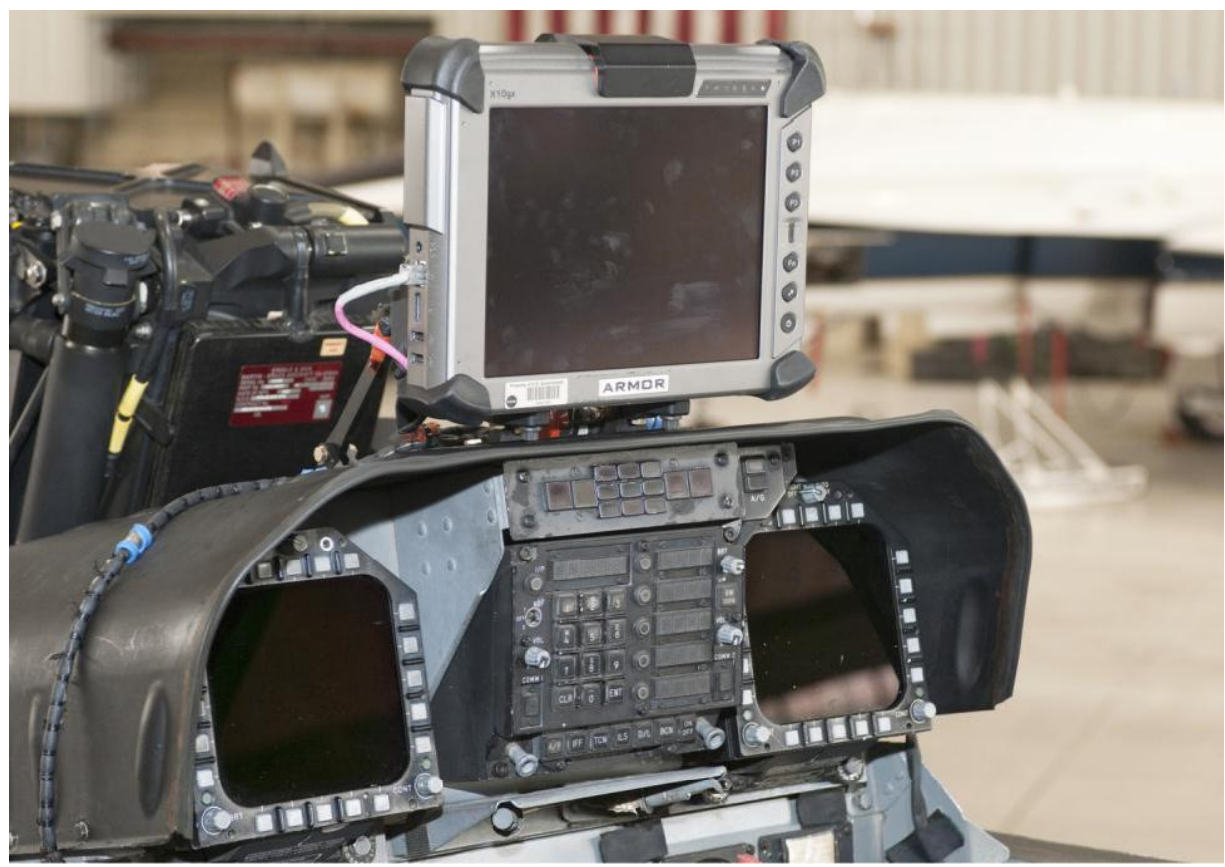

Figure 5. The MDot display mounted in the rear cockpit of F-18B tail number 852.

For the PCBoom6 computation of focused boom location, the first time derivatives of Mach number and flight path angle and heading are needed. ${ }^{1}$ These derivatives (referred to as MDot, GammaDot, and PsiDot) are not normally displayed in an F-18B airplane, so the MDot display was developed. An approximation to Mach number and flight path angle were determined from the airplane's F-18B inertial navigation system (INS) -measured speed components and the airplane-measured ambient temperature. These values were then numerically differentiated and displayed to the rear seat pilot of the F-18B as milliMDot and GammaDot. MilliMDot was used for viewing convenience and is calculated as the first derivative of Mach number multiplied by 1,000.

Mach number is given by Eq. (1), and then approximated by Eq. (2) by neglecting the wind components.

$$
\begin{gathered}
M=\frac{\sqrt{\left(V_{n}-W_{n}\right)^{2}+\left(V_{e}-W_{e}\right)^{2}+\left(V_{d}-W_{d}\right)^{2}}}{a} \\
M \approx \frac{\sqrt{V_{n}^{2}+V_{e}^{2}+V_{d}^{2}}}{a}
\end{gathered}
$$

Even though the numerator in Eq. (2) is an inertial speed and the denominator is an airspeed, the neglected wind speed in the numerator will drop out of the derivative computation if the wind is constant. This assumption will not hold when diving through a wind shear. The flight path angle was approximated as shown in Eq. (3).

$$
\gamma \approx \tan ^{-1}\left(\frac{-V_{d}}{\sqrt{V_{n}^{2}+V_{e}^{2}}}\right) \frac{180}{\pi}
$$

Similarly, the winds are neglected because constant winds drop out when the derivative is taken. For each time point the 20 most recent time-tagged Mach and flight path angle approximations were fit to a line using least squares to determine MDot and GammaDot. The update rate of these data is 24.8 samples per second.

Since no SCAMP maneuvers involved a heading change, the derivative of heading was not displayed. The pilot was able to keep PsiDot at zero by keeping a constant course direction. The approximations of Eqs. (2) and (3) work well at a constant altitude where the winds are constant, but have some errors during dives because the wind vector changes with altitude. It would have been preferable to utilize corrected airdata measurements for the MDot display, 
but these were not available from the Ethernet gateway device in the configuration that was available at the time of the test.

The functionality of the MDot display was partially verified during a taxi test of the aircraft. Repeated hard accelerations and brakings were performed to generate milliMDot values of around $+/-8$. These values were verified with differentiated aircraft GPS data.

Since the INS of the airplane can experience reported position drift of hundreds to thousands of feet, ${ }^{10}$ a handheld GPS was used in the front cockpit to guide the airplane to the correct waypoints from which to begin the maneuvers. It was difficult to find an appropriate level of zoom on the display of the handheld GPS, as the unit was designed for general aviation aircraft use but in this application was being used at Mach 1.1. A carrier-phase differential GPS receiver was used for postflight values of inertial position and velocity.

After the SCAMP flights were complete, the aircraft Mach number was at first determined from the production pitot-static probes on each side of the radome, as well as the angle-of-attack sensor. The Boeing production aircraft calibrations were applied, and then an additional correction to Mach number for supersonic Mach numbers was also incorporated to increase the accuracy of Mach number for postflight analysis. ${ }^{10}$ The additional correction gave repeatable data to within Mach 0.002 in level flight (neglecting the larger errors for rapid deceleration in the transonic region) but there are remaining errors that occur in diving flight. Figure 6 shows the computed Mach number correction for a level altitude acceleration in red. The data match fairly well (within Mach 0.002) with the calibration obtained in 2007 (shown in black) from the data in Ref. 10. Repeating the same analysis for flight in dives of two different rates, shown in blue and green, the computed Mach correction bifurcates into larger hysteresis loops.

Three separate attempts were made to account for the hysteresis loop, assuming that it was due to pneumatic lag. For the first attempt the pneumatic system of the airplane was pressurized to values slightly above and below ambient pressure while the airplane was in the hangar. The tubing was then allowed to nearly instantaneously vent to ambient pressure in order to measure the pneumatic response to a step function of pressure, and thereby determine the pneumatic lag coefficients. ${ }^{11}$ Unfortunately, no lag was perceived with this setup; that is, the pressure vented to ambient pressure was within one sample of the RQDS instrumentation-system-recorded pressure (1/24.8 of $1 \mathrm{~s})$. It was felt that at ground-level pressures the lag was too small to measure, but appreciable lag occurs at flight altitude.

The second attempt used an airdata test unit controlled by a software program to apply the same pressures measured during a SCAMP dive, again while the airplane was in the hangar. A second research airdata instrumentation system from a T-34 airplane (Hawker Beechcraft Corporation, Wichita, Kansas) was used externally to measure the pressures at the pitot-static tubes while the RQDS system measured the pressures along with any effects from pneumatic lag. Probable timing errors between the two instrumentation systems yielded data that showed the RQDS-measured pressure leading the pressure measured at the pitot-static tube, which is an impossibility. There are plans for higher-rate instrumentation systems to be used with more accurate time-tagging, but such a system was not available to be used before the publication of this paper.

The third attempt to determine the pneumatic lag involved assuming a mathematical model of the $\operatorname{lag}^{12}$ and adjusting the lag constants for total and static pressure to collapse the blue and green curves shown in Fig. 6 . For the two dives shown in Fig. 6 a static pressure lag constant of approximately $0.125 \mathrm{~s}$ and a total pressure lag constant of zero greatly reduced the hysteresis loop at some Mach numbers but not others, and did not give consistent improvement at zero or different dive rates. For post-flight SCAMP sonic boom analysis the Mach numbers during dives were derived from balloon-measured temperature and aircraft GPS data instead of the measured pneumatic data to avoid errors from pneumatic lag. The accurate determination of sonic boom locations is dependent upon an accurate knowledge of Mach number, thus, future aircraft would benefit from pitot-static systems that have low pneumatic lag. 


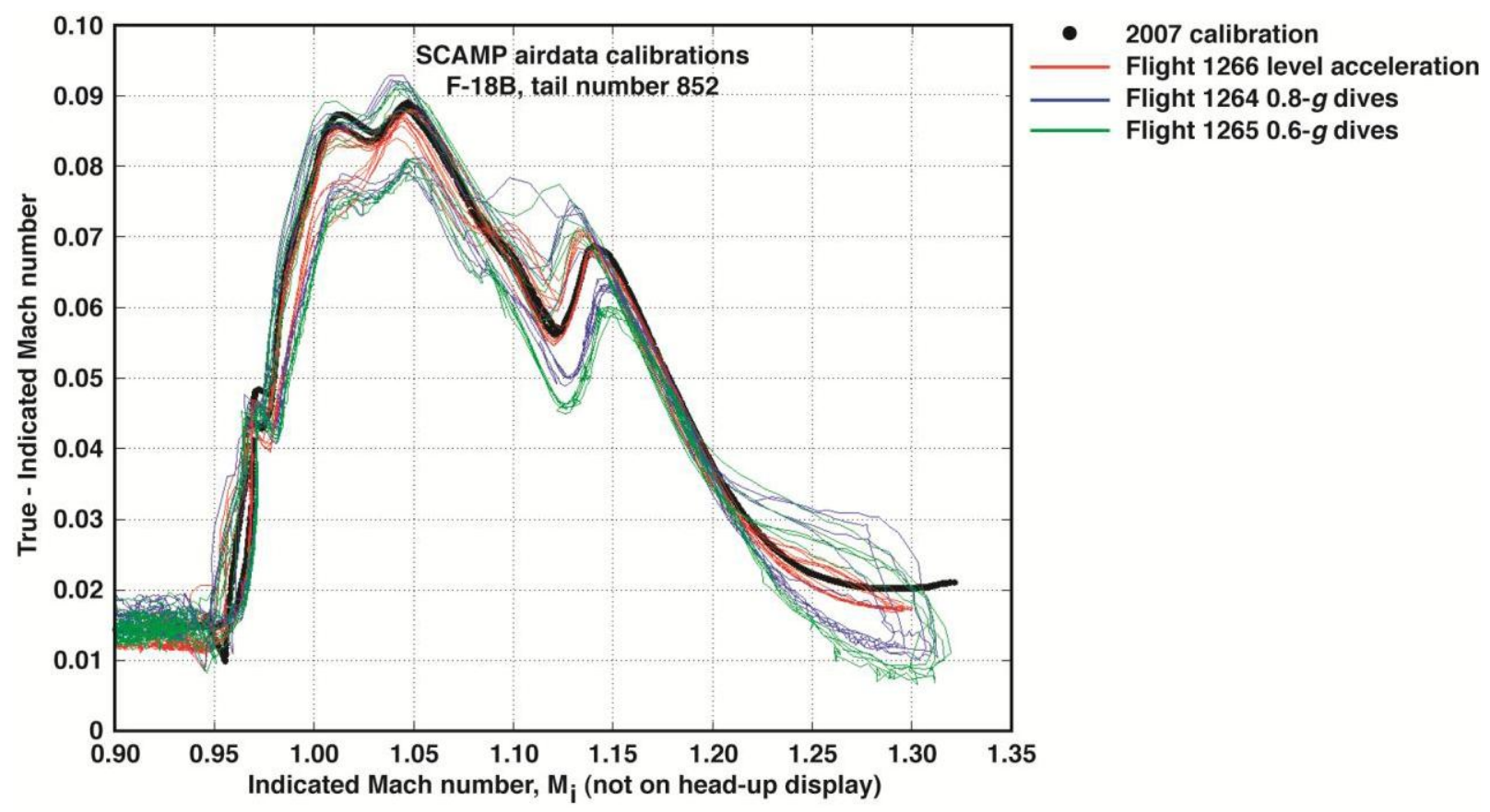

Figure 6. The SCAMP airdata calibration curves from level accelerations and dives of different rates.

\section{TG-14 Instrumentation}

The TG-14 motorized glider, tail number 149, shown in Fig. 7, was used to measure the sonic booms for SCAMP above ground-level turbulence. The TG-14 motorized glider is on loan from the United States Air Force Test Pilot School (Edwards, California) and is equipped with acoustic sensors to make up the Airborne Acoustic Measurement Platform, or AAMP. Figure 8 shows the wingtip-mounted 0.5-inch condenser microphone with a low-frequency adapter, tapered nose cone, and preamplifier. This setup was connected to the instrumentation pallet in the cargo area shown in Fig. 9. The microphone was amplified and then digitized by an analog-to-digital converter. The cockpit audio was also digitized. Software hosted on a tablet personal computer was used to record the data. Additionally, GPS-based IRIG-B timecode generator data was also recorded. A carrier-phase differential GPS receiver measured the position and velocity of the TG-14 motorized glider. All of these systems were battery-powered. 


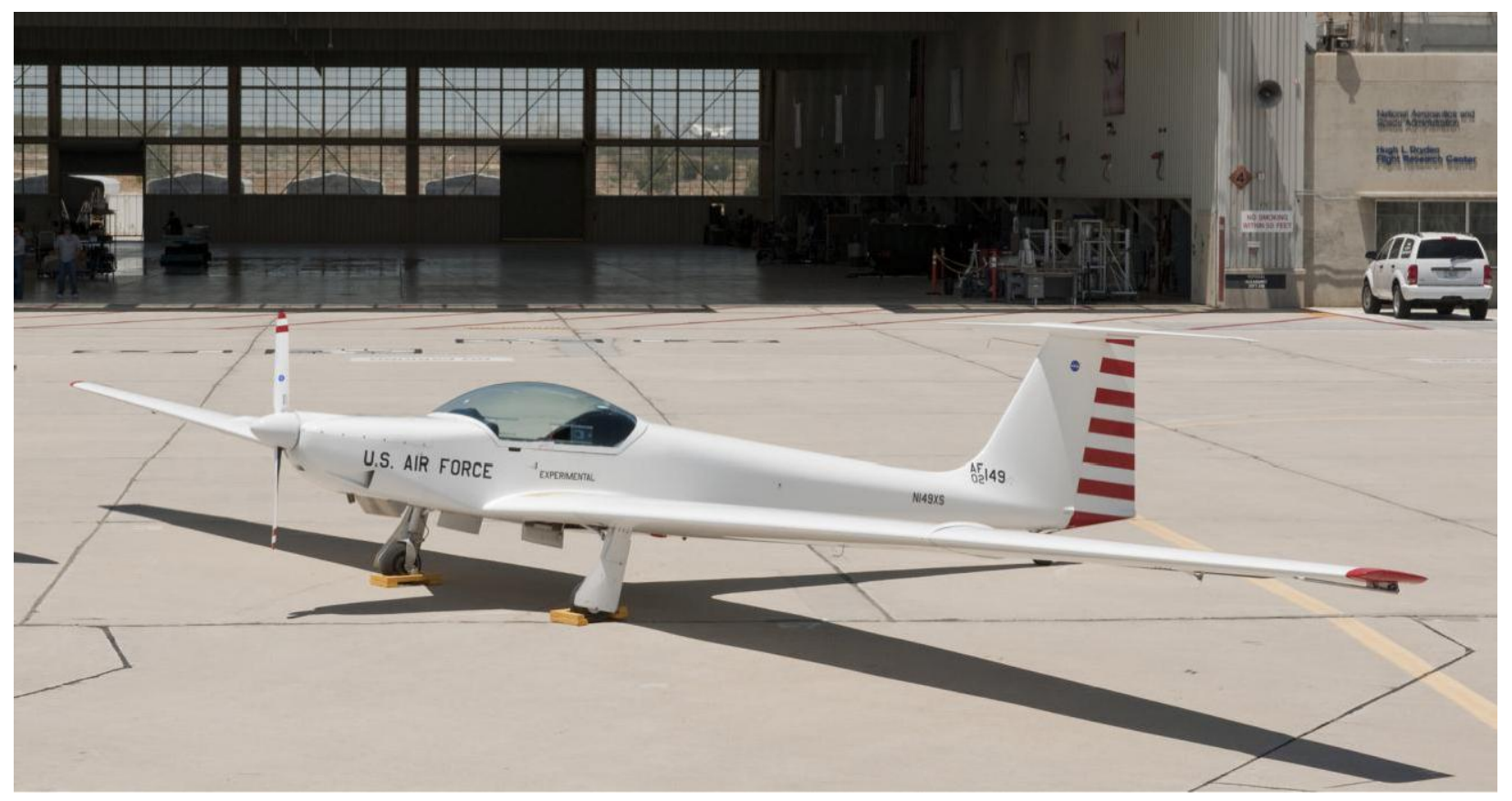

Figure 7. The TG-14 motorized glider, tail number 149.

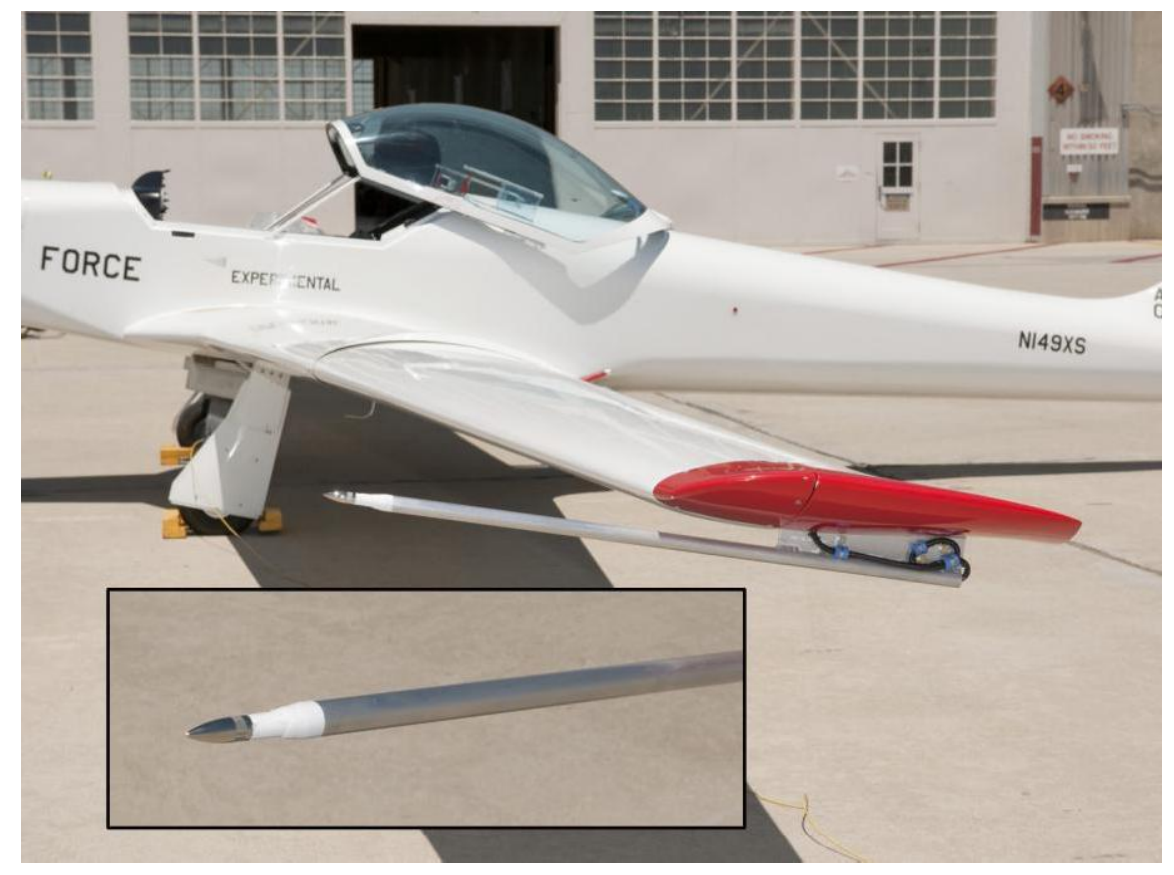

Figure 8. The wingtip-mounted microphone on the TG-14 motorized glider, with inset closeup of microphone. 


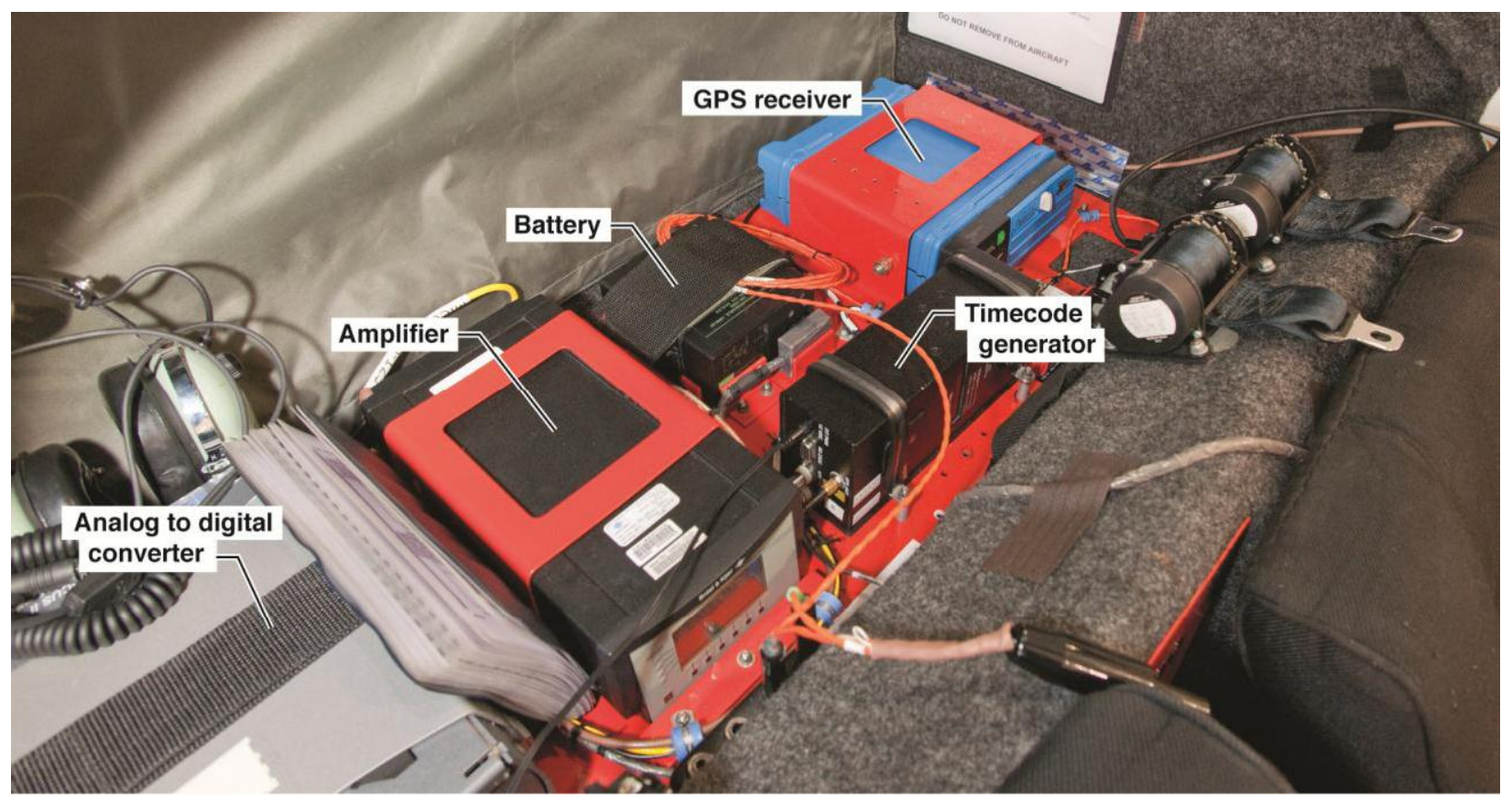

Figure 9. The TG-14 instrumentation pallet. From left to right: analog to digital converter; amplifier, battery, GPS-based IRIG-B timecode generator, GPS receiver.

It was discovered during checkout flights that the microphone portion of the AAMP system would not record properly during powered flight. Prior to recording sonic booms the engine of the TG-14 was turned off, and the data were collected during gliding flight. The engine was restarted to position the TG-14 motorized glider for the next supersonic pass of the F-18B airplane. Positioning of the TG-14 motorized glider was aided by a handheld GPS receiver.

\section{Maneuvers}

The four focused sonic boom maneuvers designed for SCAMP are denoted by the letters A through D (Alpha through Delta), shown in Table 2.

Table 2. The SCAMP F-18B flight maneuvers.

\begin{tabular}{|l|c|c|c|c|c|}
\hline Maneuver & $\begin{array}{c}\text { Initial pressure } \\
\text { altitude, } \mathrm{ft}\end{array}$ & milliMDot, /s & Throttle & GammaDot, deg/s & $\begin{array}{c}\text { Normal } \\
\text { acceleration, } g\end{array}$ \\
\hline Alpha & 35000 & 3.5 & Variable & 0 & 1.0 \\
\hline Bravo & 35000 & Variable & Constant & 0 & 1.0 \\
\hline Charlie & 45000 & 3.5 & Variable & -0.25 & 0.8 \\
\hline Delta & 45000 & 3.5 & Variable & -0.50 & 0.6 \\
\hline
\end{tabular}

Maneuvers Alpha and Bravo were selected to mimic the likely trajectory of a civilian supersonic aircraft. Maneuvers Charlie and Delta were designed in order to cover a larger range of caustic curvatures that civilian supersonic aircraft may generate with greater thrust-to-weight ratios, even though these future aircraft will not typically be diving while in supersonic acceleration. The same caustic can be generated through either a higher MDot or through a large negative Gammadot, or some combination of the two. ${ }^{13}$

An important tool for the development of these maneuvers was the NASA Dryden F-18 simulator, which included a real-time display of sonic booms that would reach the ground, using the Cockpit Interactive Sonic Boom Display Avionics (CISBoomDA) software. ${ }^{14}$ The RQDS, Ethernet gateway device, and the MDot display were removed from F-18B tail number 852 and installed in the F-18 simulator (Fig. 4). The project pilots tried a multitude of level and diving accelerations in the simulator while project engineers monitored the sonic boom footprints evolving in real time on the map display. The maneuvers were refined for ease of execution and repeatability to 
develop the four maneuvers represented in Table 2. Various MDot display derivative polynomial functions were investigated in the F-18 simulator to determine the proper order of curve fit and the number of samples to use. The order of the polynomial and the number of samples were adjusted until the pilots had acceptable control of MDot and GammaDot in the F-18 simulator. Using the previous 20 samples and a first-order polynomial proved to have the best characteristics for the pilots to be able to maintain a constant MDot or GammaDot in the F-18 simulator.

The execution of all four of these maneuvers had the same desired setup. The aircraft was to be flown at the desired initial altitude to reach Mach 1.1 and the desired value of MDot at the true heading of 92 deg (parallel to the ground microphone array) when reaching the desired waypoint. The pilot would provide time-to-go calls before the waypoints of two minutes, one minute, 30 seconds, and then a call of "5-4-3-2-1-MARK", with MARK occurring at the waypoint. Upon reaching the waypoint the level acceleration was continued for maneuvers Alpha and Bravo, or the dive commenced for maneuvers Charlie and Delta. For safety, to avoid ground collision, the maneuver would be terminated if any of the following three conditions were met: Mach 1.3, a pressure altitude of $19,000 \mathrm{ft}$, or a pitch angle of 35 deg below the horizon.

In flight, repeatable test points were obtained by having the rear seat pilot modulate aircraft thrust while monitoring the MDot display while the front seat pilot modulated aircraft normal acceleration. Because the front seat pilot could not see the MDot display, he used displayed normal acceleration in lieu of GammaDot, which gave nearly the same results for boom placement.

With the maneuvers defined, the hardware was reinstalled in F-18B tail number 852, and on April 28, 2011 the Alpha, Bravo, Charlie, and Delta maneuvers were flown several times as practice runs without regard to the placement of the focus. The most repeatable maneuvers were selected to be templates for all the future A, B, C, and D maneuvers. The airplane pitot-static, INS, GPS, and balloon-measured atmospheric, data were processed to ensure the post-flight Mach calibration was still valid (at least in level flight), and PCBoom6 trajectory input files were generated that contained adjustments to remove effects due to the winds of that particular day (which are called zero-wind trajectory files).

\section{Planning Software}

Software was developed to rapidly determine the F-18B starting waypoint for each of the four maneuvers given the day-of-flight balloon-measured atmospheric conditions. This software is called "Where's The Focus?" (WTF). Using the day-of-flight balloon data, WTF computed the focused boom location resulting from the day-of-flight temperature and wind profile. This interim location was typically not at the optimum location $25 \%$ along the ground array (which is at microphone number 20 out of 81) as depicted in Fig. 2. The offset between the interim and optimum focus locations was applied to the original zero-wind F-18B waypoint to yield the optimum F-18B starting waypoint, which was emailed from a person at the array to the flight crew just prior to each flight.

At the heart of the MATLAB (The MathWorks, Natick, Massachusetts) -based WTF software are calls to components of the PCBoom6 software, specifically FOBoom, ${ }^{1}$ that performs sonic boom raytracing. FOBoom produces a formatted text file (the .out file) that contains locations and impact times for every ray on the sonic boom footprint. Each time point in the trajectory input file produces one isopemp (shown in Fig. 2 as gray arcs) which is comprised of a spread of azimuthal angles (phi) left and right of the aircraft flight track. The WTF software interrogates the entire sonic boom footprint solution and finds all of the sonic boom impact points that are at a given phi angle. Most of the SCAMP data were taken at phi $=0$, but offset data at the phi angles given in Table 3 were also sought.

Table 3. The desired offtrack phi angles for the SCAMP F-18B flight maneuvers.

\begin{tabular}{|l|c|}
\hline Maneuver & Desired offtrack phi angle, deg \\
\hline Alpha & 20 \\
\hline Bravo & 30 \\
\hline Charlie & 40 \\
\hline Delta & 50 \\
\hline
\end{tabular}

Once the sonic boom impact points at a given phi angle are found, the ray that yields the earliest ground impact time is selected as being the focus location. The furthest uptrack location could have also been used, but using the earliest time is an easier solution independent of aircraft heading. It is important to note that the earliest generated boom is downtrack of the focus location and hits later due to its more shallow trajectory and long propagation path. For example, in Fig. 10 for the Delta maneuver near the tail of the solid arrow the first boom generated that hits the 
ground will occur $12 \mathrm{~s}$ after and nearly $3 \mathrm{~nm}$ downrange of the focused sonic boom. On CISBoomDA in the F-18 simulator the pilot could see during aircraft acceleration the new impact locations (or isopemps) moving opposite the flight direction, as shown by the solid arrow in Fig. 10, then starting to pile up on each other at the focus, then starting to move in the same direction as the aircraft, as shown by the dashed arrow in Fig. 10.

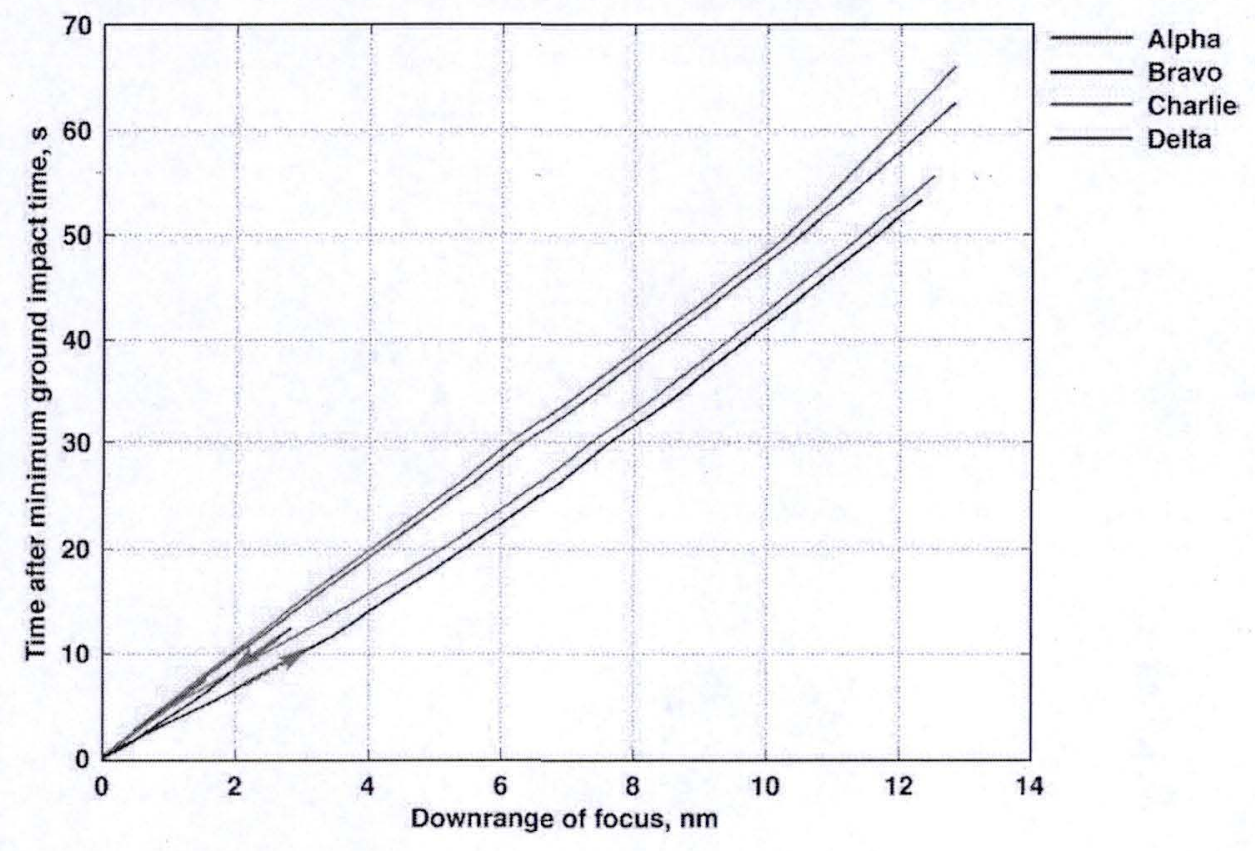

Figure 10. The PCBoom6-computed centerline impact location and time of impact for each of the four nominal SCAMP maneuvers. The solid arrow shows the initially-generated pre-focused boom for maneuver Delta, and the dashed arrow shows a boom generated later in the post-focus region.

The goal of the TG-14 pilot was to measure the sonic boom in the neighborhood of the F-18 sonic boom caustic. In order for the TG-14 motorized glider to capture the focused sonic boom a similar approach was taken to finding the focus, but with the added complexity of variable altitude and time. If the TG-14 aircraft flew at the same heading as the F-18B, there would be only one instance for a given altitude when the focus would occur, giving a very low probability of capturing a focused sonic boom. Having the TG-14 aircraft fly perpendicular to the F-18B flight track, and realizing the focused sonic boom is relatively constant in location and character within 5 deg of the desired phi angle, results in a much larger time window being available. The FOBoom program was run with the ground altitude artificially set at the 6500 pressure altitude at which the TG-14 aircraft was flying, and for the desired phi angle $+/-5 \mathrm{deg}$. The focus location was determined from the ray giving the minimum impact time. These locations were output to a file that was uploaded into the handheld GPS receiver mounted in the TG-14 aircraft. Propagation times from the F-18B waypoint to these focus locations were also emailed to the TG-14 flight crew. For each pass of the F-18B airplane, the TG-14 flight crew would use the F-18B "MARK" call to start a countdown timer and to arrive between the two $+/-5$ deg delta phi TG-14 waypoints when the timer reached zero.

\section{Adjustments Using Audible Cues}

Changes in atmospheric conditions and aircraft performance could cause variations in the focus locations, necessitating adjustment of the F-18B waypoint. With each pass, the airplane becomes lighter due to fuel consumption and its acceleration increases for a given power setting.

Immediately following the completion of the first supersonic pass, the approximate location of the point of maximum focus within the array was determined audibly by observing the acoustic events associated with the focus flight at various locations along the array. After each aircraft pass, personnel located at five stations along the 10,000 -ft-long linear microphone array were polled for what they heard, working from the uptrack to the downtrack locations along the array. This information was then used to adjust, if required, the F-18B waypoint for the next pass. The reporting personnel were trained to respond with specific types of observations, shown on the lower

12

American Institute of Aeronautics and Astronautics 
portion of Fig. 11, which also shows the development of the on-track pre-focus, focus, post-focus and carpet boom regions associated with accelerated flight of an aircraft transitioning from subsonic to supersonic speed. The top portion of the figure shows the development of the bow-shock wave and its intersection with the ground as the aircraft accelerates from $M=0.90$ to $M=1.3$. Only the bow shock is depicted. Also shown are the pressure signatures that would be observed at various positions on the ground, A through $\mathrm{H}$ along the acceleration path.

In the pre-focus region, ahead of the focus "caustic" line, the nature of the pressure disturbances are low-frequency noise signatures called evanescent waves that increase in amplitude as the focus is approached. Thus, an observer at location A may not experience any sounds, whereas at locations B and C, they would experience a "whooshing" sound, then a heavier rumbling sound, or thud, respectively. At the focus, location D, which may be on the order of $100 \mathrm{~m}$ to $200 \mathrm{~m}$ in width, an observer would experience the intense "U-shaped" focused signature as a loud BANG-BANG. In the post-focus region that follows the focus, anywhere from three to four shocks may be experienced. For example, at location E, the observer would hear a BANG-BANG-BANG, the intensity being somewhat less than that at the focus. At locations $\mathrm{F}$ and $\mathrm{G}$, where the $\mathrm{N}$-wave and $\mathrm{U}$-wave become evident, the observer would hear a less intense BANG-BANG of the N-wave followed by the "pop-pop" of the reflected "U" signature. The pop-pop is usually, but not always, lower in amplitude than the "N"-wave BANG-BANG. The cadence, that is, the time between the bang-bang-pop-pop, increases between locations F and G. Once one enters the carpet boom region, the U-wave has disappeared due to atmospheric refraction and an observer experiences only the lower level BANG-BANG of the carpet N-wave. While Fig. 11 depicts a level acceleration flight, the same pressure signatures and observations also apply to a diving acceleration.

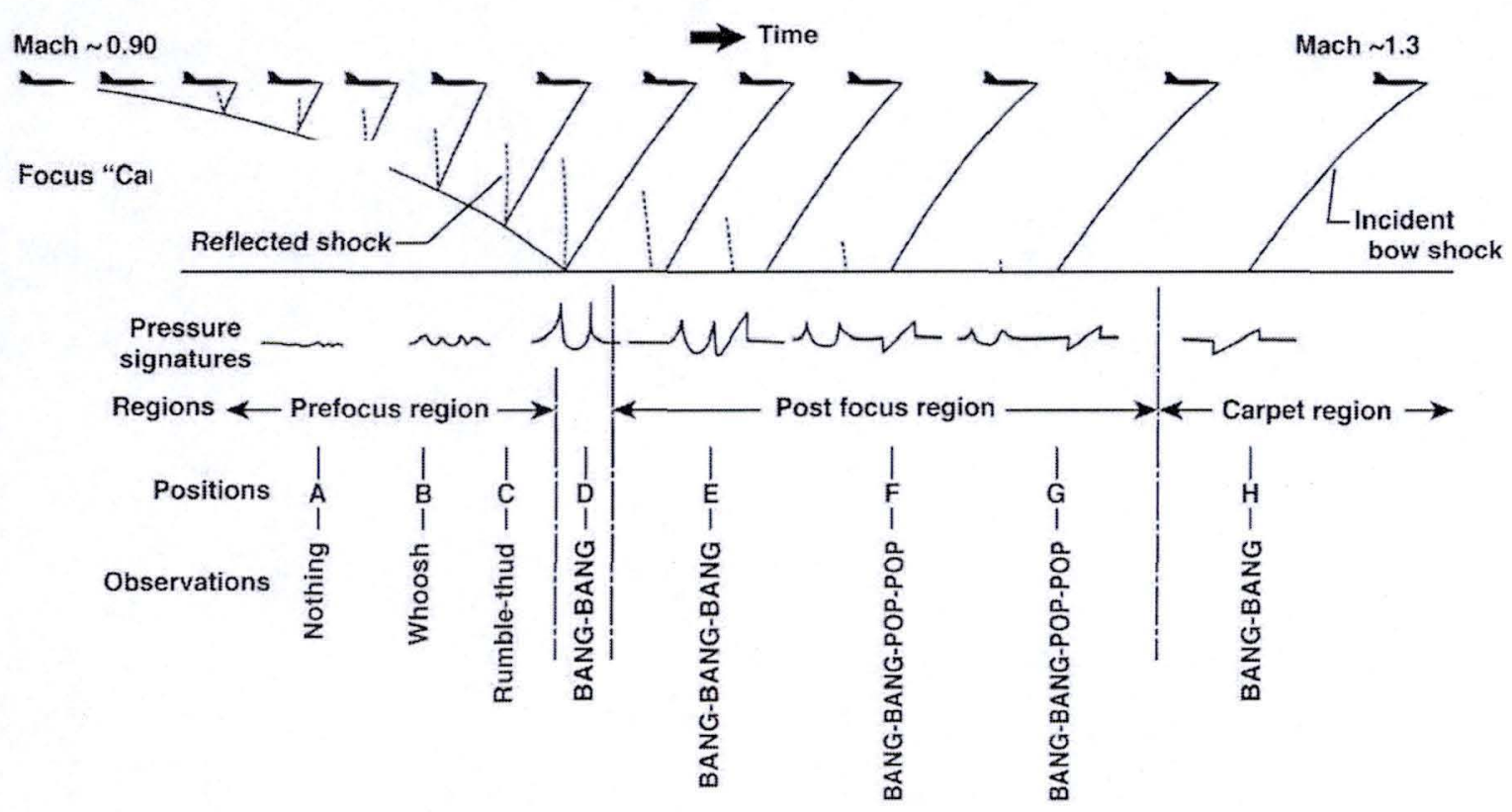

Figure 11. Transition focus and audible cues.

\section{Results}

The SCAMP team desired that the entire focus event be measured on the array, from before the evanescent wave until after the "N" wave and post-focus " $U$ " wave have separated. Of the 60 focus passes executed, 32 recordings of this nature were obtained. Eight passes of the 60 yielded maximum focus on the array, but were located near one end such that the full event was not captured. There were 20 passes of the 60 in which the focus missed the array completely.

Tables 4 through 9 show for each maneuver the focus passes attempted, the subjective perceived turbulence level of the atmosphere, the requested and measured waypoints to start the maneuver, the microphone location of the focus (both computed by PCBoom6 from the aircraft and atmospheric data as well as measured by the microphones in the array), and the offset in feet between the computed and measured focus location. For those passes for which the focus did not land on the array the approximate distance in nautical miles and direction from the nearest edge of

13

American Institute of Aeronautics and Astronautics 
the array is given as determined by PCBoom6. Table 10 gives aggregate statistics of focus placement for each of the SCAMP maneuvers.

Table 4. The focus locations for maneuver Alpha Centerline.

\begin{tabular}{|c|c|c|c|c|c|c|c|}
\hline & & & $\begin{array}{l}\text { Waypoint sl } \\
\mathrm{nm}\end{array}$ & uptrack, & $\begin{array}{l}\text { Focus locati } \\
\text { microphone } \\
\text { (20 desired) }\end{array}$ & $\begin{array}{l}\text { by } \\
\text { amber } \\
\text { if off array }\end{array}$ & $\begin{array}{l}\text { Focus offset } \\
\text { downrange, } \\
\text { PCBoom6- }\end{array}$ \\
\hline Flight & Pass & Atmosphere & Requested & Measured & PCBoom6 & Measured & \\
\hline 1262 & 1 & Turb & 0 & 0 & 71 & 65 & 750 \\
\hline 1262 & 2 & Turb & 0.5 & -0.6 & 62 & 37 & 3125 \\
\hline 1262 & 3 & Turb & 0.25 & -0.5 & 30 & 3 & 3375 \\
\hline 1262 & 4 & Turb & 0 & -0.8 & $\begin{array}{c}1 \mathrm{~nm} \\
\text { downtrack }\end{array}$ & Downtrack & - \\
\hline 1262 & 5 & Turb & 0 & -0.8 & $\begin{array}{c}1 \mathrm{~nm} \\
\text { downtrack }\end{array}$ & Downtrack & - \\
\hline 1266 & 1 & Calm & 0 & 0 & 40 & 64 & -3000 \\
\hline 1266 & 2 & Calm & 0.5 & 0.1 & $\begin{array}{c}2 \mathrm{~nm} \\
\text { downtrack }\end{array}$ & Downtrack & - \\
\hline 1266 & 3 & Calm & 0.75 & 0.7 & $\begin{array}{c}1 \mathrm{~nm} \\
\text { downtrack }\end{array}$ & Downtrack & - \\
\hline 1266 & 4 & Calm & 2 & 2.4 & 16 & 16 & 0 \\
\hline 1266 & 5 & Calm & 2 & 1.8 & 49 & 58 & -1125 \\
\hline 1266 & 6 & Calm & 2 & 1.8 & 54 & 65 & -1375 \\
\hline
\end{tabular}

14

American Institute of Aeronautics and Astronautics 
Table 5. The focus locations for maneuver Alpha Offset.

\begin{tabular}{|c|c|c|c|c|c|c|c|}
\hline & & & \multicolumn{2}{|c|}{$\begin{array}{l}\text { Waypoint shift uptrack, } \\
\mathrm{nm}\end{array}$} & \multicolumn{2}{|c|}{$\begin{array}{l}\text { Focus location by } \\
\text { microphone number } \\
\text { ( } 20 \text { desired), or if off array }\end{array}$} & \multirow{2}{*}{$\begin{array}{l}\text { Focus offset } \\
\text { downrange, } \\
\text { PCBoom6- } \\
\text { measured, } \\
\mathrm{ft}\end{array}$} \\
\hline Flight & Pass & Atmosphere & Requested & Measured & PCBoom6 & Measured & \\
\hline 1268 & 1 & Calm & 0 & $\begin{array}{c}-0.1 \\
(0.1 \text { right of } \\
\text { track })\end{array}$ & $\begin{array}{c}2 \mathrm{~nm} \\
\text { downtrack }\end{array}$ & Downtrack & - \\
\hline 1268 & 2 & Calm & 0 & $\begin{array}{l}-0.1 \\
(0.1 \text { right of } \\
\text { track })\end{array}$ & $\begin{array}{c}2 \mathrm{~nm} \\
\text { downtrack }\end{array}$ & Downtrack & - \\
\hline 1268 & 3 & Calm & 2 & $\begin{array}{c}2.4 \\
(0.4 \text { left of } \\
\text { track }) \\
\end{array}$ & $\begin{array}{c}0.5 \mathrm{~nm} \\
\text { downtrack }\end{array}$ & Downtrack & - \\
\hline 1268 & 4 & Calm & 4 & $\begin{array}{c}6.1 \\
(0.5 \text { left of } \\
\text { track })\end{array}$ & $\begin{array}{c}3 \mathrm{~nm} \\
\text { uptrack }\end{array}$ & Uptrack & - \\
\hline 1268 & 5 & Calm & 3.5 & 3.4 & $\begin{array}{c}0.5 \mathrm{~nm} \\
\text { downtrack }\end{array}$ & Downtrack & - \\
\hline 1268 & 6 & Calm & 4 & 4.0 & $\begin{array}{c}1 \mathrm{~nm} \\
\text { downtrack }\end{array}$ & Downtrack & - \\
\hline 1272 & 1 & Calm & 0 & 0.1 & $\begin{array}{c}\text { Uptrack } \\
\text { and } \\
\text { downtrack, } \\
\text { but not on } \\
\text { the array }\end{array}$ & - & - \\
\hline 1272 & 2 & Calm & -0.25 & $\begin{array}{c}-0.4 \\
(0.1 \text { right of } \\
\text { track })\end{array}$ & $\begin{array}{c}0.5 \mathrm{~nm} \\
\text { downtrack }\end{array}$ & 33 & - \\
\hline 1272 & 3 & Calm & -0.25 & $\begin{array}{l}0.0 \\
(0.1 \text { right of } \\
\text { track })\end{array}$ & $\begin{array}{c}1.6 \mathrm{~nm} \\
\text { downtrack }\end{array}$ & Downtrack & - \\
\hline 1272 & 4 & Calm & $\begin{array}{l}\text { Not } \\
\text { recorded }\end{array}$ & $\begin{array}{l}0.1 \\
(0.1 \text { right of } \\
\text { track })\end{array}$ & 6 & 28 & -2750 \\
\hline 1272 & 5 & Calm & $\begin{array}{l}\text { Not } \\
\text { recorded }\end{array}$ & 0.0 & $\begin{array}{c}2 \mathrm{~nm} \\
\text { downtrack }\end{array}$ & Downtrack & - \\
\hline 1274 & 4 & Calm & 0 & $\begin{array}{l}0.2 \\
(0.5 \text { right of } \\
\text { track })\end{array}$ & $\begin{array}{c}1 \mathrm{~nm} \\
\text { downtrack }\end{array}$ & Downtrack & - \\
\hline 1274 & 5 & Calm & 0 & $\begin{array}{c}0.0 \\
(0.6 \text { right of } \\
\text { track })\end{array}$ & $\begin{array}{c}\text { Processing } \\
\text { error }\end{array}$ & Downtrack & - \\
\hline
\end{tabular}


Table 6. The focus locations for maneuver Bravo Centerline.

\begin{tabular}{|c|c|c|c|c|c|c|c|}
\hline \multirow[b]{2}{*}{ Flight } & \multirow[b]{2}{*}{ Pass } & \multirow[b]{2}{*}{ Atmosphere } & \multicolumn{2}{|c|}{$\begin{array}{l}\text { Waypoint shift uptrack, } \\
\mathrm{nm}\end{array}$} & \multicolumn{2}{|c|}{$\begin{array}{l}\text { Focus location by } \\
\text { microphone number } \\
\text { ( } 20 \text { desired), or if off array }\end{array}$} & \multirow{2}{*}{$\begin{array}{l}\text { Focus offset } \\
\text { downrange, } \\
\text { PCBoom6- } \\
\text { measured, } \\
\mathrm{ft} \\
\end{array}$} \\
\hline & & & Requested & Measured & PCBoom6 & Measured & \\
\hline 1263 & 1 & Turb & 0 & 0 & 62 & 71 & -1125 \\
\hline 1263 & 2 & Turb & 0 & 0.6 & $\begin{array}{r}0.5 \mathrm{~nm} \\
\text { uptrack }\end{array}$ & Uptrack & - \\
\hline 1263 & 3 & Turb & 0 & 0.5 & $\begin{array}{l}0.2 \mathrm{~nm} \\
\text { uptrack }\end{array}$ & Uptrack & - \\
\hline 1263 & 4 & Turb & -0.5 & 0 & 51 & 18 & 4125 \\
\hline 1263 & 5 & Turb & -1 & -0.4 & $\begin{array}{c}0.2 \mathrm{~nm} \\
\text { downtrack }\end{array}$ & 59 & - \\
\hline 1263 & 6 & Turb & -1 & -0.3 & 45 & 47 & -250 \\
\hline 1267 & 1 & Calm & 0 & 0 & $\begin{array}{c}2 \mathrm{~nm} \\
\text { downtrack }\end{array}$ & Downtrack & - \\
\hline 1267 & 2 & Calm & 2 & 2.1 & 60 & 69 & -1125 \\
\hline 1267 & 3 & Calm & 2 & 1.3 & 53 & 55 & -250 \\
\hline 1267 & 4 & Calm & 2 & 1.3 & 62 & 65 & -375 \\
\hline 1267 & 5 & Calm & 2.25 & 1.6 & 63 & 63 & 0 \\
\hline 1267 & 6 & Calm & 2.75 & 2.1 & 46 & 49 & -375 \\
\hline 1267 & 7 & Calm & 3.25 & 2.9 & $\begin{array}{c}0.5 \mathrm{~nm} \\
\text { downtrack }\end{array}$ & downtrack & - \\
\hline
\end{tabular}

Table 7. The focus locations for maneuver Charlie Centerline.

\begin{tabular}{|l|c|c|c|c|c|c|c|}
\hline & & & & \multicolumn{2}{l}{$\begin{array}{l}\text { Waypoint shift uptrack, } \\
\text { nm }\end{array}$} & & \multicolumn{2}{l|}{$\begin{array}{l}\text { Focus location by } \\
\text { microphone number } \\
\text { (20 desired), or if off array }\end{array}$} & $\begin{array}{l}\text { Focus offset } \\
\text { downrange, } \\
\text { PCBoom6- } \\
\text { measured, } \\
\mathrm{ft}\end{array}$ \\
\hline Flight & Pass & Atmosphere & Requested & Measured & PCBoom6 & Measured & \\
\hline 1264 & 1 & Calm & 0 & 0 & 18 & 22 & -500 \\
\hline 1264 & 2 & Calm & 0 & 0 & 33 & 39 & -750 \\
\hline 1264 & 3 & Calm & 0 & 0 & 50 & 52 & -250 \\
\hline 1264 & 4 & Calm & 0 & 0 & 56 & 60 & -500 \\
\hline 1264 & 5 & Calm & 0 & -0.1 & 38 & 38 & 0 \\
\hline 1269 & 1 & Calm & 0 & 0 & Uptrack & Uptrack & \\
\hline 1269 & 2 & Calm & 1 & 1.1 & 21 & 21 & 0 \\
\hline 1269 & 3 & Calm & 0.75 & 0.4 & 51 & 51 & 0 \\
\hline 1269 & 4 & Calm & 0.75 & 0.3 & 73 & 74 & -125 \\
\hline 1270 & 1 & Calm & 0 & 0 & 19 & 15 & 500 \\
\hline 1270 & 2 & Calm & 0.25 & 0.3 & 37 & 33 & 500 \\
\hline 1270 & 3 & Calm & 0.25 & 0.3 & 31 & 26 & 625 \\
\hline 1270 & 4 & Calm & 0.25 & 0.2 & 18 & 17 & 125 \\
\hline 1270 & 5 & Calm & 0.25 & 0.1 & 23 & 18 & 625 \\
\hline
\end{tabular}

16

American Institute of Aeronautics and Astronautics 
Table 8. The focus locations for maneuver Charlie Offset.

\begin{tabular}{|c|c|c|c|c|c|c|c|}
\hline \multirow[b]{2}{*}{ Flight } & \multirow[b]{2}{*}{ Pass } & \multirow[b]{2}{*}{ Atmosphere } & \multicolumn{2}{|c|}{$\begin{array}{l}\text { Waypoint shift uptrack, } \\
\mathrm{nm}\end{array}$} & \multicolumn{2}{|c|}{$\begin{array}{l}\text { Focus location by } \\
\text { microphone number } \\
\text { ( } 20 \text { desired), or if off array }\end{array}$} & \multirow{2}{*}{$\begin{array}{l}\text { Focus offset } \\
\text { downrange, } \\
\text { PCBoom6- } \\
\text { measured, } \\
\mathrm{ft}\end{array}$} \\
\hline & & & Requested & Measured & PCBoom6 & Measured & \\
\hline 1273 & 1 & Calm & ( & $\begin{array}{c}0 \\
(0.1 \text { Right } \\
\text { of Track })\end{array}$ & 68 & 67 & 125 \\
\hline 1273 & 2 & Calm & 0 & 0.1 & 53 & 52 & 125 \\
\hline 1273 & 3 & Calm & 0 & $\begin{array}{c}0 \\
(0.1 \text { Right } \\
\text { of Track }) \\
\end{array}$ & 47 & 44 & 375 \\
\hline 1273 & 4 & Calm & 0 & $\begin{array}{c}0 \\
(0.2 \text { Right } \\
\text { of Track })\end{array}$ & 47 & 46 & 125 \\
\hline
\end{tabular}

Table 9. The focus locations for maneuver Delta Centerline.

\begin{tabular}{|c|c|c|c|c|c|c|c|}
\hline \multirow[b]{2}{*}{ Flight } & \multirow[b]{2}{*}{ Pass } & \multirow[b]{2}{*}{ Atmosphere } & \multicolumn{2}{|c|}{$\begin{array}{l}\text { Waypoint shift uptrack, } \\
\text { nm }\end{array}$} & \multicolumn{2}{|c|}{$\begin{array}{l}\text { Focus location by } \\
\text { microphone number } \\
\text { ( } 20 \text { desired), or if off array }\end{array}$} & \multirow{2}{*}{$\begin{array}{l}\text { Focus offset } \\
\text { downrange, } \\
\text { PCBoom6- } \\
\text { measured, } \\
\mathrm{ft}\end{array}$} \\
\hline & & & Requested & Measured & PCBoom6 & Measured & \\
\hline 1265 & 1 & Calm & 0 & 0 & 76 & 76 & 0 \\
\hline 1265 & 2 & Calm & 0.5 & 0.1 & 43 & 42 & 125 \\
\hline 1265 & 3 & Calm & 0.5 & 0.3 & 25 & 24 & 125 \\
\hline 1265 & 4 & Calm & 0.5 & 0.4 & 21 & 21 & 0 \\
\hline 1265 & 5 & Calm & 0.5 & 0.3 & 30 & 30 & 0 \\
\hline
\end{tabular}

Table 10. The SCAMP maneuver focus accuracy statistics.

\begin{tabular}{|l|c|c|c|}
\hline Maneuver & $\begin{array}{l}\text { Average caustic } \\
\text { elevation above } \\
\text { horizontal, deg }\end{array}$ & $\begin{array}{l}\text { Success } \\
\text { placing focus } \\
\text { on the array, } \%\end{array}$ & $\begin{array}{l}\text { Focus } \\
\text { offset range, ft }\end{array}$ \\
\hline Alpha Offset & 15 & 15 & 2750 \\
\hline Alpha Centerline & 19 & 64 & $0-3000$ \\
\hline Bravo Centerline & 20 & 69 & $0-4125$ \\
\hline Charlie Offset & 28 & 100 & $125-375$ \\
\hline Charlie Centerline & 39 & 93 & $0-750$ \\
\hline Delta Centerline & 54 & 100 & $0-125$ \\
\hline
\end{tabular}

17

American Institute of Aeronautics and Astronautics 
It is evident from Table 10 that there was a much higher success rate for the two diving maneuvers than for the level accelerations, for which there are five reasons:

1. As shown in Table 10, the angle of the sonic boom caustic to the ground is much lower for the level accelerations than for the dives. This magnifies small Mach and positional errors to greater errors of the focus location along the ground.

2. MDot is a much weaker effector of focus location than GammaDot, and the pilot has much greater control of GammaDot through the indicated normal acceleration than of MDot as controlled by engine setting. Additionally, the level accelerations are solely dependent on the engines for MDot control, whereas the dives primarily use gravity to increase MDot.

3. The addition of a specific geographic waypoint to the maneuver is an added complication that sometimes impedes the proper establishment of MDot. For approximately half of the Alpha Offset maneuvers, most of the Bravo maneuvers, and one of the Charlie maneuvers, the pilots needed to greatly retard the throttle prior to the waypoint, sometimes to negative MDot, but then the engines could not immediately resume the needed MDot when the maneuver began. With high gradients in MDot the chance for using the incorrect value in PCBoom6 increases, which corrupts the focus location calculation. For some maneuvers the pilot was a bit slower than the requested Mach 1.1 at the waypoint, and the extra needed distance to get to the proper speed pushed the focus past the microphone array.

4. For flight 1262 for maneuver Alpha Centerline the local balloon malfunctioned, so a balloon approximately $30 \mathrm{~nm}$ away was used. The spatial variation of the temperature and wind profile over that distance would induce more errors into the focus location calculations.

5. Using the audible cues to shift the focus cannot work accurately if none of the observers hear the focus. The team could tell if the focus was downtrack or uptrack of the array, but did not know the distance the waypoint needed to be shifted until the first focus was detected. The Alpha Offset statistics suffered greatly for this reason. Had a real-time computation of focus location been available to the pilot or flight controllers the focus could have been more accurately placed on the microphone array. This was shown using CISBoomDA in the F-18 simulator.

In spite of these difficulties, a large database of focused booms at different flight conditions was gathered and used to validate several focused sonic boom propagation computational codes. ${ }^{15,16}$ For maneuvers that do not have shallow caustics (such as maneuvers Charlie and Delta) or high MDot derivatives, the focused boom locations were computed to be within a few hundred feet of their measured locations

The TG-14 motorized glider was also used yielding the first measurement of sonic booms above the Earth's turbulent boundary layer in the evanescent region, on the caustic, and in the post-focus region for the same flight condition. Table 11 shows results of the measurements taken by the TG-14 motorized glider.

Table 11. The measurements taken by the TG-14 motorized glider.

\begin{tabular}{|l|c|c|}
\hline Flight & Pass & Boom type measured \\
\hline 1264 & 1 & - \\
\hline 1264 & 3 & Evanescent wave \\
\hline 1264 & 4 & Focus \\
\hline 1264 & 5 & N-u \\
\hline 1266 & 1 & N-u combined \\
\hline 1266 & 2 & - \\
\hline 1266 & 3 & - \\
\hline 1266 & 4 & N-u overlap \\
\hline 1266 & 5 & Evanescent wave \\
\hline 1266 & 6 & Evanescent wave \\
\hline 1267 & 1 & - \\
\hline 1267 & 2 & N-u overlap \\
\hline 1267 & 3 & - \\
\hline 1267 & 4 & - \\
\hline 1267 & 5 & Evanescent wave \\
\hline 1267 & 6 & Evanescent wave \\
\hline 1267 & 7 & - \\
\hline
\end{tabular}

18

American Institute of Aeronautics and Astronautics 
The TG-14 motorized glider flew six flights over the array, but on three of those flights there were instrumentation problems that prevented recording microphone data. On the three other flights shown in Table 11, five evanescent waves, one focused sonic boom, and four $\mathrm{N}$-u waves in the post-focus region were measured out of 17 recording attempts, a success rate of 59\%. The TG-14 aircraft had the most difficult acquisition task as timing was another flight constraint. The variability from the focus hitting microphone number 20 as shown in Tables 4,6 , and 7 added additional uncertainty to capturing the caustic. A fair amount of luck was involved to capture an evanescent wave, a focus, and a N-u wave for the same maneuver on flight 1264.

\section{Concluding Remarks}

The methods given in this paper for the determination of focused sonic boom location and aircraft waypoints were very successful in accurate placements of these booms on the Superboom Caustic Analysis Measurement Project (SCAMP) microphone array and for the motorized glider. This dataset will be used for the validation of new focused sonic boom computational codes. A technique was outlined that developed template maneuver data from simulator and flight data, and these data were processed through the PCBoom6 software to compute focused boom locations for the weather conditions of the test day. The computed minimum ground impact time data were used as the focus. A new cockpit display showing the first time derivatives of Mach number and flight path angle was developed to aid in consistent maneuvers. The motorized glider waypoints were selected to intersect the caustic surface perpendicular to the supersonic airplane flight path to increase the chances of capturing the focused sonic boom. The use of audible cues to shift the supersonic airplane waypoints improved the placement of the focused sonic booms on the array, as long as the focus location could be heard.

The data show that $67 \%$ of the foci were placed on the 10,000 -ft-long microphone array, with a $96 \%$ success rate for runs with large caustic elevation angles (greater than or equal to $28 \mathrm{deg}$ ) to the horizon. The PCBoom6 computations of the focus locations from atmospheric and aircraft data agreed with the measured focus locations to within a few hundred feet for large caustic elevations to a few thousand feet for some low caustic elevations. It is felt that this agreement can be improved for low caustic elevations with better instrumentation (including a method to measure winds aloft; and a low-lag pitot-static system) and pilot displays such as CISBoomDA. The motorized glider was able to capture sonic boom data on $59 \%$ of runs when the instrumentation was operating properly.

A future quiet supersonic aircraft will likely generate a caustic that has a shallow angle to the ground. It is likely that the focused sonic boom from a quiet supersonic aircraft may need to be kept away from noise-sensitive areas, and so focused boom location management will be required.

The following recommendations are made for accurate focused boom placement:

- An accurate airdata system, with low pneumatic lag

- The use of timely and local atmospheric data from the ground to flight altitude

- Accurate knowledge of the engine performance and resultant MDot of the aircraft

- The use of a cockpit sonic boom display, showing both currently generated and upcoming sonic boom impact locations and magnitudes

- The use of piloting cues or an autopilot to predictably place the focused sonic boom at a desired location.

\section{Acknowledgments}

This project was sponsored by the National Aeronautics and Space Administration. The Superboom Caustic Analysis and Measurement Project (SCAMP) flight validation effort was part of a NASA Research Announcement contract with Wyle (El Segundo, California) and their subcontractors: The Pennsylvania State University (University Park, Pennsylvania); Gulfstream Aerospace Corporation (Savannah, Georgia); Eagle Aeronautics (Newport News, Virginia); Central Washington University (Ellensburg, Washington); and The Boeing Company (Chicago, Illinois). The NASA Langley Research Center (Hampton, Virginia) provided Contracting services, as well as extensive measurement equipment and field operators. The NASA Dryden Flight Research Center (Edwards, California) provided flight research aircraft, flight and sonic boom planning, and measurement systems, and the NASA Marshall Space Flight Center (Huntsville, Alabama) loaned the project long lengths of microphone cable. The Boeing Company provided extensive field equipment and support well beyond their contractual obligations.

Computer Sciences Corporation (CSC) (Falls Church, Virginia); Arcata Associates, Inc. (Huntsville, Alabama); The TYBRIN Group (Ft. Walton Beach, Florida); and The Wackenhut Corporation (now G4S Government 
Solutions, Palm Gardens, Florida) as contractors to NASA Dryden respectively provided aircraft maintenance, control room resources and support, weather support, and security support.

The United States Department of the Interior Bureau of Land Management (Washington DC) granted access to the measurement site near Cuddeback Dry Lake, with biological services provided by the $95^{\text {th }}$ Air Base Wing at Edwards Air Force Base, California. The National Geospatial-Intelligence Agency (Ft. Belvoir, Virginia) performed surveying duties, and the United States Air Force Test Pilot School (Edwards, California) loaned the TG-14 motorized glider to NASA. The Air Force Research Laboratory (Wright-Patterson Air Force Base, Ohio) loaned microphones to the project.

In addition, several organizations participated in the flight measurement program in the field at their own cost, their only payment being access to the flight data. Northrop Grumman Corporation (Falls Church, Virginia) supplied $16 \%$ of the ground microphone array and personnel; Cessna Aircraft Company (Textron Inc., Providence, Rhode Island) provided the blimp, its airborne microphones, and personnel. Two post-doctoral students from Nagoya University (Nagoya, Japan) provided two and one-half weeks of manual labor setting up and operating the microphone array. Seismic Warning Systems (Scotts Valley, California) deployed seismometers, and MetroLaser, Inc. (Irvine, California) deployed a ground-to-air Schlieren camera to image the F-18 shock waves.

The F-18B research instrumentation included a TrueTime ${ }^{\circledR}$ Model GPS-705 (Symmetricom, Inc., San Jose, California) timecode generator; an Ashtech Z-12 ${ }^{\mathrm{TM}}$ (Magellan Corporation, Santa Clara, California) differential GPS; an Ethernet gateway by NetAcquire (Kirkland, Washington), and an ARMOR X10gx (ARMOR Rugged Mobile Computers, Melbourne, Florida) personal computer for the MDot display. The second airdata lag test used a Barfield (Barfield, Inc., Miami, Florida) DPS500 digital pitot static test set controlled by software written in NI LabVIEW (National Instruments Corporation, Austin, Texas). The TG-14 motorized glider used a Brüel \& Kjærr (B\&K) (Naerum, Denmark) model 4193 microphone, a B\&K model UC0211 low-frequency adapter, a B\&K model UA0386 tapered nose cone, a B\&K model 2669-C preamplifier, and a B\&K model 2690-A-OS2 Nexus amplifier. The data were digitized on the airplane with a LDS Dactron (B\&K) FOCUS II analog-to-digital converter using LDS Dactron RT Pro software on a Fujitsu P1630 (Tokyo, Japan) personal computer. Timing data were provided by an Instrumentation Technology Systems model 6155D (Information Technology Systems, Northridge, California) timecode generator, and airplane position and velocity were measured with an Ashtech Z-Xtreme differential GPS. A Garmin GPSMAP 496 (Olathe, Kansas) GPS was used by the motorized glider pilot. 


\section{References}

'Page, J. A., Plotkin, K. J., and Wilmer, C., "PCBoom Version 6.6 Technical Reference and User Manual," Wyle Report WR 10-10, March 2010.

${ }^{2}$ Kerr, T. H., "Experience of Supersonic Flying over Land in the United Kingdorn", AGARD-R-250, 1959.

${ }^{3}$ Hubbard, H. H., Maglieri, D. J., Huckel, V., and Hilton, D. A., "Ground Measurements of Sonic-Boom Pressures for the Altitude Range of 10,000 to 75,000 feet,"NASA TR R-198, 1964.

${ }^{4}$ Maglieri, D. J., Hilton, D. A., and McLeod, N. J., "Experiments on the Effects of Atmospheric Refraction and Airplane Accelerations on Sonic-Boom Ground-Pressure Patterns," NASA TN D-3520, 1966.

${ }^{5}$ Vallée J., "Mesure de l'intesité des bangs soniques engendres par un avion Volant en palier accéléré supersonique, Opération Jéricho - Focalisation," Centre d'Essais en Vol, Annexe d'Istres, Rapport d-etude no. 272, 1967.

6 Vallée J., "Etude expérimentale des focalisations de bangs soniques engendrées par le vol supersonique en accélération rectiligne ou en virage d'un avion Mirage IV à l'altitude $11000 \mathrm{~m}$, Opération Jéricho - Virage," Centre d'Essais en Vol, Annexe d'Istres, Rapport de-etude no. 277, 1969.

${ }^{7}$ Wanner, J-C. L., Vallée, J., Vivier, C., and Thery, C, "Theoretical and Experimental Studies of the Focus of Sonic Booms," The Journal of the Acoustical Society of America, Vol. 52, No. 1 (Part 1), pp. 13-32, 1972.

${ }^{8}$ Haglund, G. T., and Kane, E. J., "Flight Test Measurements and Analysis of Sonic Boom Phenomena Near the Shock Wave Extremity,"NASA CR-2167, 1973

${ }^{9}$ Downing, M., et al., "Measurement of Controlled Focused Sonic Booms from Maneuvering Aircratt," USAF/AL-OE-WP-TR$1997-0185,1998$.

${ }^{10}$ Haering, E. A. Jr., Cliatt, L. J. II, Bunce, T. J., Gabrielson, T. B., Sparrow, V. W, and Locey, L. L., "Initial Results from the Variable Intensity Sonic Boom Propagation Database," AIAA-2008-3034, 2008.

"Whitmore, S. A., Haering, E. A. Jr., and Ehernberger, L. J., "An Optimal Deconvolution Method for Reconstructing Pneumatically Distorted Near-Field Sonic Boom Pressure Measurement,"NASA TP-4000, 1996.

${ }^{12}$ Huston, W., "Accuracy of Airspeed Measurements and Flight Calibration Procedures," NACA-TR-919, 1948.

13 Plotkin, K. J, and Maglieri, D., "SCAMP: Experimental Design of a Sonic Boom Focus Flight Test," 51st AIAA Aerospace Sciences Meeting Including the New Horizons Fonum and Aerospace Exposition, American Institute of Aeronautics and Astronautics, Reston, Virginia (submitted for publication).

${ }^{14}$ Haering, E. A. Jr., and Plotkin, K. J., "Real-Time, Interactive Sonic Boom Display," U. S. Patent No. 8, 145,366 B1, March 27 , 2012.

${ }^{15}$ Salamone, J.A., Sparrow, V., and Cowart, R. "SCAMP: Solution of the Lossy Nonlinear Tricomi Equation for Sonic Boom Focusing," 51st AIAA Aerospace Sciences Meeting Including the New Horizons Forum and Aerospace Exposition, American Institute of Aeronautics and Astronautics. Reston, Virginia (submitted for publication).

${ }_{16}$ Piacsek, A. A., "SCAMP: Application of Nonlinear Progressive-wave Equation to Sonic Boom Transition Focus," 51st AlAA Aerospace Sciences Meeting Including the New Horizons Forum and Aerospace Exposition, American Institute of Aeronautics and Astronautics, Reston, Virginia (submitted for publication), 